\title{
What MAKeS a GoOd ASSESSMEnt? ASSESSMEnTS FOR LEARNING
}

\author{
Michael Stachowsky and Andrew J B Milne \\ University of Waterloo Engineering First Year Office, and Department of Mechanical and Mechatronics Engineering \\ mstachowsky@uwaterloo.ca, ajbmilne@uwaterloo.ca
}

\begin{abstract}
We present in this paper a 'how-to' framework for designing motivating assessments, based upon the cognitive theories of expectancy-value and of aligned and authentic objectives. The framework recasts these cognitive theories into more practical steps of determining objectives, setting expectations, and framing the assessment to be well scoped, authentic, and relatable. In the Fall 2017 offering of our Introduction to Mechanical Engineering course, two new short design challenges and one long design challenge were piloted after being designed according to the objectives-expectations-framing framework. In each case, the assessments were designed to be (to varying extents) engaging/authentic (something that students would want to do), and doable/relatable (something the students could do). The term long project (of largest scope, authenticity, and relatability) was found by student survey to be the most motivating. Of the two smaller projects, the second, while seemingly more authentic and relatable, was found to be less motivating. We understand this to be due to the context of this assessment coming during a time in the term when student were busy with the term design project and other courses.
\end{abstract}

Keywords: Assessment, Design, Motivation, Alignment, Objectives, Expectations, Authentic Assessment, Relatable Assessment, Impact of Engineering

\section{INTRODUCTION}

As instructors, we know that there is a long period of hard work between a student entering our programs and their graduation from them. With this, students' motivation can wax and wane. Engineering students are expected to spend, on average, approximately $60 \mathrm{hrs} / \mathrm{week}$ on academic work. With only 20-24 hours/week in class, the majority of student time is spent outside of class (doing readings, homework, labs, or other assessments which all constitute either assessments/assessments, or preparation for them). Student success is therefore influenced by how students use these out-of-class hours. How they use them is in turn influenced by how motivated, or not, students are by the assessments we set for them.
There are a number of factors, both intrinsic and extrinsic, that motivate a student to choose to study engineering. Bennet et al [1] studied Canadian engineering first year students and determined that many students choose engineering because they are intrinsically motivated by the prospects of what they will learn and the contributions they will make. Responses included choosing engineering because of subject matter ("I enjoy math and physics"), broad themes of their education ("I love the concept of space exploration") and what the students will do in their careers ("I enjoy working on technological innovation"). Bennet did not study students who reported having low motivation for their studies. In contrast, Dubreta and Milos [2] broke incoming engineering students into three groups based on their selfproclaimed motivations - those who were motivated to study engineering, those who were uncertain of whether engineering was the right choice, and those who claimed to not be motivated at all. From this, we see that one must consider the motivational effects of assessment to help unmotivated students in engineering programs.

We seek in this paper to lay the ground work for the design of motivating assessments. After presenting (Section 2) an outline of existing research on cognitive models of student motivation (what is going on in students heads) we aim in this paper (Section 3) and the future to develop a 'how-to' framework to guide course instructors in designing motivating assessments that align with multiple objective, have clearly defined and explained expectations, and are well scoped. While we are working toward a practical framework, we hope it will allow some faculty an entry point to the wider world of more theoretical research on cognitive models of motivation. We close (Section 4) by discussing three assessments designed using the framework and piloted in ME 100 (the introduction to the profession course for first year Mechanical Engineering students at the University of Waterloo) in F17. The discussion will focus on the successes and failures in motivating students in these assessments

We hope, in designing better assessments, to lead to improved student learning. We also hope, as instructors of first-year courses, that our assessments can serve as a 
motivating or corrective intervention for incoming students. As instructional designers, we face the challenge of maintaining motivation in eager students while encouraging students to find their motivation if they are uncertain, or to decide early in their studies that a field is not for them.

\section{BACKGROUND - COGNITIVE MODELS OF STUDENT ENGAGEMENT}

\subsection{Expectancy-Value Theory}

A well-studied theory of motivation, engagement, and performance is the so-called Expectancy-Value theory, first proposed in the 1950s by Wigfield and Eccles [3], and expanded upon by Svinicki [4]. According to Wigfield, "beliefs about one's ability play a prominent role in different motivation theories". Whether a student believes that they are competent enough to succeed is often a strong factor in whether or not they will succeed. Expectancyvalue theory explains these beliefs in terms of two concepts, expectations and values.

Expectations relate to how well one expects to do at a given task given our self-assessment of one's abilities and the challenge of said task. Values relate to how well one wants to do on the task and how much they value the perceived outcome of the work. For instance, a student may think they will do very well on a math test provided that they study, but may not be motivated to do so since they don't value that test very highly (it may be for bonus marks, for example), or they may not see the value of math to engineering. Therefore that student's performance might be low despite their ability.

An interesting facet of student valuation of an activity is the cost involved in undertaking it [3]. Students evaluate the cost of spending time on one activity over another. So, for the example above, another reason a math test may be seen as not valuable to a student is because they may have other seemingly more important things to do inside or outside of classes. This is an indication that the context in which the assessment is given is an important factor in whether it will be engaging. The right assessment given at the wrong time may fail to engage students despite good design.

We argue that by designing an assessment in which students expect to succeed, and in which they value that success, student motivation and engagement will increase. Further, we seek in Section 3 to define what characteristics a course instructor can consider in designing an assessment to meet these targets.

\subsection{Aligned Authentic Objectives}

In addition to the motivating effects of expectation and value, researchers have examined how aligned and authentic objectives/intended learning outcomes can affect student motivation. Simon and Taylor [5] demonstrates that a clear understanding by students and instructors of instructional alignment, or how well an instructional activity aligns with intended learning outcomes, is a major positive influence in students' perceptions of their learning.

Others, such as Wellington et al. [6] have pointed out that authentic assessments are more motivating. Wellinton et al. describe authentic assessments as 'any type of assessment that requires student to demonstrate skills and competencies that realistically represent problems and situations likely to be encountered in daily life'. The daily life of engineering students (after graduation) is work in the profession of engineering. For students at the University of Waterloo especially, the frequency of co-op terms means that UW students are especially interested in being taught and tested on authentic (real-world) knowledge.

\subsection{Additional factors influencing student engagement}

In this paper we are primarily interested in developing a framework that instructional designers can use to create more engaging/motivating assessments or other activities, in order to increase student performance and, ultimately, learning. Beyond the factors outlines in Sections 2.1-2.2, there are a number of reasons that students engage with assessments. Some are within the power of the instructional designer to control, and others are beyond it.

Smith et al [7] and Shekhar and Borrego [8] both studied increasing student engagement via collaboration in teams. Collaboration, especially where students are clearly useful and appreciated, is a strong motivator. We embrace this, but do not limit our framework specifically to collaborative activities, as we feel that there is a place for individual work as well.

Engagement in an engineering program goes beyond having only engaging activities. Chen et al [9] notes that there is a strong correlation between faculty engagement and student engagement - if the faculty is interested in what and how they teach, students will pick up on this and feel valued. Lopez et al [10] studied student motivation in a broader context of remaining motivated throughout an entire engineering student career. Lopez's work implies that student motivation can be increased by good activity design (a majority of their sample population selfidentified as being interested in self-development through challenging experiences) but also that there are other factors, include out-of-school life, which can cause a student to become demotivated.

In Svinicki [4], additional factors related to value and expectancy driven motivation are described. Specifically, the influence and encouragement/example of others (which contribute to both value and expectancy), and beliefs about self-efficacy, locus of control, and growth mindset (which all contribute to expectancy). Also, she notes in students a drive in students to either work toward mastery in a subject or to focus on performance at the expense of learning. We see interaction of others as a tool that can be applied to 
assessment design to improve motivation that can either be internal (e.g. assessments assigned to teams of students), or external (e.g. peer review and feedback, or peer assessment). These could be considered as either part of the context of the assessment or the expectations. Conversely, we see beliefs in self-efficacy, locus of control, and growth mindset as student beliefs that are not directly addressable by assessment design. Svinicki discusses several systemic interventions that are needed for some students, especially those who don't consider themselves to have "natural" ability. These interventions require sustained effort throughout the students' careers. We direct readers to the work of Svinicki [4] for instructional strategies that can attempt to budge student beliefs in these factors, and an area for future research is if well designed assessments can serve as a teaching tool to budge student beliefs in these areas.

We do not seek to solve all of the motivational roadblocks that students face in this paper. We argue, however, that solid instructional design with the goal of increasing engagement as much as possible in our activities will provide students with avenues to remain engaged if other factors are demotivating them.

\section{TOWARD A 'HOW-TO' FRAMEWORK FOR DESIGNING MOTIVATING ASSESSMENTS}

Informed by the work of Wigfield, Svinicki and others, we present in Figure 1 a 'how-to' frame work for instructor designing assessments. The framework depends on assessments: having clear objectives (for the students and the instructor), having clear expectations (that are clearly communicated to students), and being well framed (for students). The focus of this paper is the frame of the assessment, which for us consists of the scope of the work, its authenticity, and its relatability. Important in our framework is the hypothesis that within the frame of the assessment, there must be a balancing of the scope, authenticity, and relatability, in that if one aspect moves in a direction that is demotivating, one or both of the others must move in the opposite direction. It is also important to note that we see our framework as one to follow for continued refinement of assessment design. After designing and running an assessment, is it important to return and reconsider the objectives, expectations, and framing of the assessment.

\subsection{Objectives}

One can have multiple objectives for designing and assigning an assessment. Assessments can be for, as, or of learning. That is, they can be formative (giving instructors an objective and/or subjective assessment of our teaching, in order to better design learning materials in the future, or giving students a formative objective and/or subjective assessment of their learning). They can be a learning tool (setting out to teach students something of value in the act of doing them). Finally, they can be summative (being a 'final' measure of the amount of learning that has taken place). We presume that readers already have intended learning outcomes or objectives for their students, and know which of these are being addressed in a given assessment to be designed. We further presume that any personal objectives regarding assessments of teaching have been decided on.

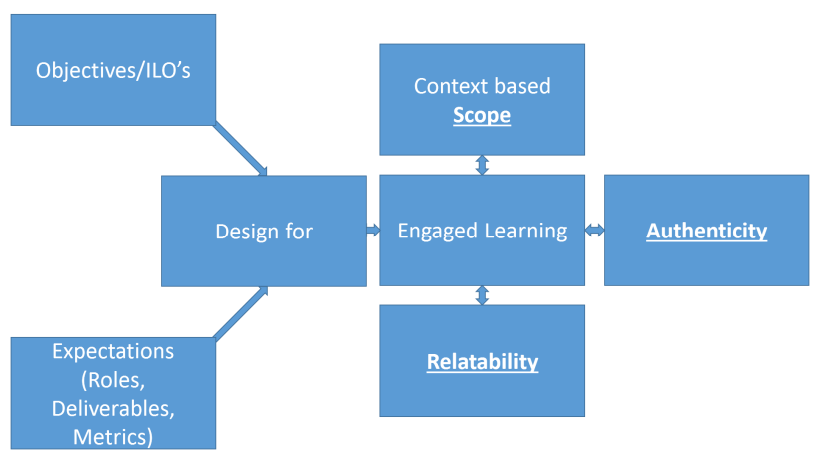

Figure 1: Schematic of a 'how-to' frame work for designing motivating assessments.

\subsection{Expectations}

After considering the objectives of an assessment, we next propose considering how objectives and expectations for student behavior align. Expectations for students include their role (how they are expected to act), and the degree of open endedness of their deliverables/evaluation (who controls the form of the final result and determination of quality).

3.2.1. Roles. Defining roles helps students to understand the level of formality and maturity that they are expected to use when engaging in this activity. The role of the student lies on a spectrum, from "playful explorer" to "professional".

- Playful explorer: this role communicates that the activity is informal, designed to encourage experimentation, in which the end result is the experience of having done it.

- Professional: this role communicates that the activity is to be treated with the level of maturity that would be expected of a working professional. The students are expected to perform to their highest standard and will be evaluated based on their ability to maintain that standard.

At this early stage of developing the framework, we propose that the spectrum of roles from playful to professional interfaces (imperfectly) with the theory of mastery versus performance driven learning [4]. If one of our objectives for students is for them to strive to become masters in a field, and if we wish them to be motivated thusly, they must explore it, willing to (happily) find 
roadblocks and unknowns. When we expect a high standard, we run the risk of driving student toward performance learning. We feel it should be possible to call for professional level work that is still mastery driven, as (professional) faculty can engage in mastery driven work and learning that is professionally completed and communicated, but how best to do this with students remains an area of research.

3.2.2. Open Endedness. Assessments can be open ended or closed, or somewhere in between, again lying on a spectrum:

- Open ended: an open ended assessment gives students guidelines on what is expected, but does not give them a checklist of items to gauge their own success, or a specific subject of work. Emphasis is put on the students' abilities to choose and size a subject, determine if they are correct, and reflect objectively on the quality of their own work.

- Closed: on the other end of the spectrum, closed assessments offer a clear checklist of marks that students can obtain, and clear, objective measures by which students can determine if they will get a certain mark.

Regardless of whether a given assessment is being designed to for playful exploration or professional work, and if it is open ended or closed, we believe that student motivation is helped by clearly communicating the expectations of student behavior, and the reasons for expecting such behaviour. This is because it removes an uncertainty from students' minds, allowing them to determine if they have the necessary background to expect success in a given role (and to take corrective steps if necessary). This should also emphasize that students have an internal locus of control of their eventual success on an assessment, within the expectations set out by the instructor.

\subsection{Frame}

The frame (or framing) of the assessment is the 'sandbox' in which the students work. It defines the boundaries around the activity. It contextualizes the activity and must exist within a larger context. It gives the students something(s) to work on (the object(s) of study) and something(s) to do (the deliverable(s)). The framing of an assessment answer the questions, "where am I working, with what, what should I do, and why should I care?" There are three main components of motivation for the frame: scope, authenticity, and relatability.

Defining a motivating scope requires consideration of three things: the objects of study, the size of the activity, and the student context. The objects of study are the things that define the activity. They provide the student with something(s) to focus on (an equation, a circuit, a car).
These objects exist within a larger field, and the size, or extents, of the assessment must be considered to define the area within which we expect students to work (considering the AC response of a circuit, but not the high voltage response), the type of deliverable (a paper, a design, an object) and the amount of effort we expect students to put in (hours spent, words written, products produced). The objects of study and the extents of the assessment should be aligned with the objectives and expectations of the assessment. More ambitious objectives, or more involved expectations, will require a large scope of the assessment. However, the scope of an assessment obviously exists within the larger context of the students other commitments. Students come in to an assessment activity with their own stories, which evolve on long and short time scales. One should consider therefore: what might be going on in their heads right now? what other pressures are they under inside and outside of classes? what are they learning/doing in other courses? If the available scope for an assessment does not align with the desired objectives/expectations then students are likely to feel a low expectancy for success, leading to low motivation in an assessment. This leaves aside, for the moment, the question of students who take an otherwise well scoped assessment and procrastinate until it is a poorly scoped to their time remaining. It is hoped that well aligned and motivating assessments will help with this matter.

One can, and should, also consider the authenticity and relatability of the objects/area of study and the deliverables expected. Authenticity is the degree to which the activity, its objects of study, and the deliverables represent what students will see outside of the classroom. Authenticity answers the question "why am I learning this/when will I use this?" An authentic activity (dissection and analysis of an engine) is likely motivating (providing it is scoped), since it appeals to real world utility. However, an inauthentic deliverable (explain the analysis of the engine through interpretive dance) is demotivating. Savage et al [11] suggests that being able to understand the practical relevance of an activity is a strong motivating factor for students. In first year engineering, we hypothesize that authentic activities can help uncertain or unmotivated students to better understand what engineering is likely to be like for them. Such activities may help to either motivate them or inform them that they need to reconsider their choices. For students who are already motivated to study engineering, providing "real" experiences may give them reason to explore concepts they are passionate about in more depth. Care must be taken, however, that assessments are relatable, so as to not alienate and demotivate students who do not feel they can relate to a given authentic assessment.

Relatability, in comparison to authenticity, is a measure of the degree to which students can currently 
internalize and tell a personal story about the object of study. Relatability deals with the question, "what does this mean to me right now?" By relatable activities we mean activities that students can discuss in terms of their personal contexts. Activities that are relatable can help students to tell a personal story about what they are learning, and connect it to their lives now. It has been suggested [3] that a person who values what they are learning tends to be more engaged and will perform better.

Relatability is distinct from (and sometimes at odds with) authenticity since it requires students to have a connection to an assessment right now, whereas authenticity can, and often does, connect an assessment to future use. In this way, authentic assessments can be seen to relate to value driven motivators [4], in that the address perceived (future) needs and utility, and tend to be intrinsically motivating in their study as they are related to 'real' work that students expect to do upon graduation/on work terms. In contract, relatability corresponds to expectancy driven motivators as it requires a consideration of the prior experience and match with skills of students right now. Svinicki recommends balancing the difficulty and skills of the students (the scope and relatability/authenticity) in order to achieve 'flow' [4]. She also recommends just-in-time teaching (matching required skill instruction to the period in which is it required for an assessment) as a means of improving perceived value through utility. We see this as a way of maintaining relatability (an in-the-present expectancy motivator) while allowing for more authenticity (an in-the-future value motivator). Just-in-time teaching can be used either in longer projects, or as one or more short assessments that are timed to coincide with materials being covered at that point in a course.

\subsection{Balance and Iteration:}

As stated at the start of this section, we hypothesize that within the frame of the assessment, there must be a balancing of the scope, authenticity, and relatability. For example, when designing an activity, it is not necessary to always have authentic, relatable, context-relevant objects of study. It is often preferable to reduce one or more of these things in order to make an instructional point. For instance, we might use a basic, quarter-car model to teach the concept of coupled differential equations. This model is relatable, as students have travelled in cars. It is authentic in that cars are experienced in the outside world and students might expect to work on them, but is inauthentic in that the model is not faithful to an actual car's suspension. However, the scope of the project (the time that students have to spend on the activity) may be such that working on a full car model would be demotivating in terms of accessibility/difficulty and time required compared to time available.

We close by emphasizing that we see our framework as one to follow for continued refinement of assessment design. As discussed in Section 4, we have used this framework in developing assessments for the F17 offering of ME 100. Having piloted these assessments we are returning to the framework to rework them, as described below.

\section{TESTING THE FRAMEWORK}

We tested this framework on three assessments in ME100, a first-year concepts course for mechanical engineering at the University of Waterloo. The course has approximately 221 students in two roughly equal sections, and is given to all incoming mechanical engineering students. It is a design-focused course in which students are required to use newly learned design skills in a major cumulative project, as well as in two smaller projects. These projects are all team-based. The course has the following learning objectives that are relevant for the remainder of this discussion (the objectives are paraphrased for brevity):

1. To communicate like an engineer

2. To demonstrate skills by thinking and acting like an engineer

3. To know and apply an engineering design process

4. To explain what mechanical engineering is, and know if students are in the right program

The three assessments that were tested were (in order of appearance in the course):

1. (Course) Activity Design project: students took a concept/topic from an upper year course and did a short conceptual designed for a demonstration or other activity around it.

2. Toy Design project: design and build a prototype toy working with industry mentors.

3. (Social) Impact design project: design a solution to increase personal positive social or environmental impact.

\subsection{Activity Design Project}

For the future course activity design project, students were asked to investigate a concept/topic from an upperyear course, and prepare an introductory activity related to that topic. Using the framework, the following decisions were made:

- Authenticity: this assessment was not designed to be authentic, as it is not expected that students, or practicing engineers, will generally be required to design course materials.

- Relatability: this assessment was designed to be highly relatable. Students will be taking these courses, and the 
hope was that they would enjoy exploring the future of their careers as students. However, it is not necessarily currently relatable since we asked students to design an activity for an upper year course (to avoid students falling back on their high school physics knowledge)

- Context: this assessment was given in the beginning of the term (week 3 to 4 ), when students are eager to explore university life. They were otherwise unburdened by other assessments in their courses.

- Expectations: Students were expected to playfully explore the topic and present their findings in a relatively informal but professional way. The expectations for rigour were low, and this was communicated to students.

\subsection{Toy Design Project}

Students were paired with industry partners from Spin Master Inc. an international toy company headquartered in Toronto, Ontario, and were given guidance throughout the semester on the feasibility and marketability of their designs. Using the framework, the following decisions were made:

- Authenticity: This assessment was highly authentic, as it involved working with industrial partners on potential realworld products.

- Relatability: this assessment was highly relatable, as students have had direct experience with toys and the concept of play.

- Context: this assessment stretched throughout the term and represented a major output of the students for this course. The students were required to balance a heavy workload with high expectations. Students were expecting this project from near the start of term (week 4) and started thinking about it early.

- Expectations: students were expected to act professionally and make a strong case for their product. The interaction with industry mentors required students to be well-prepared and ready to interact with seasoned professionals on a similar level.

\subsection{Impact Design Project}

Students were tasked with analyzing their own social impact, and designing a solution that would increase their positive social impact. They were required to design a solution that could be implemented based on their current skillset, and were required to produce a product information sheet as though they were in a startup company.

- Authenticity: This assessment was designed to be somewhat authentic. Students were encouraged to explore any aspect of their own social impact, regardless of whether it related directly to engineering. They were instructed to approach the problem like engineers.
- Relatability: This assessment required the students to find something in their own lives to design a solution for, and as a result was designed to be highly relatable.

- Context: this assessment was given during their final project, assigned in week 8 , and due in week 12 . The course was 13 weeks long, with the symposium and draft report for the cumulative project occurring in week 11 .

- Expectations: students were required to act as though they were trying to pitch their solution to one of the authors. They were required to decide what level of formality would best communicate and 'sell' their solution, and could be less formal if it met the needs of their communication.

\subsection{Student Opinion Survey}

An end-of-term survey was given to the students in which they were asked questions regarding (amoung other topics) the three assessments outlined above. Students were asked to report if the assessments were important ( 5 point scale of 'not at all important' to 'extremely important', reported here as $0-4)$, made them feel like an engineer (5 point scale from 'strongly disagree' to 'strongly agree' reported here as 0-4), were doable with their present skill (same scale as 'feel like an engineer'), and whether students were felt engaged in the activity, with students prompted that engagement was related to if they enjoyed doing the activity (same scale as 'feel like an engineer'). Of approximately 212 students, approximately 134 responded to the survey, with most responding to all questions. This high response rate was achieved by assigning a $0.5 \%$ bonus mark to completion of the survey.

Figure 2 through Figure 5 show students' reporting on whether the three main design assessments in ME 100 were: important, made them feel like engineers, were doable, and were engaging (enjoyable). We propose here that 'importance' and 'feeling like an engineer' are related to authenticity (or value). We further propose that an assessment being 'doable' with current skills is an (imperfect) measure of relatability (or expectancy). Finally, we use 'engaging' as a proxy for 'motivating'. The survey questions are imperfectly matched to the framework nomenclature due to the concurrent development of the assessments, survey instrument, and framework.

We entered into analysis with the hypothesis that students would rank the toy design project the highest in terms of authenticity, relatability, and motivation. This is shown to the true in the survey results. We further expected that the impact design assignment would be more authentic and relatable. This is also borne out by survey results, with students rating the impact assessment and activity design assessment as equally important, but rating the impact assessment as one that made them feel more like engineers. The activity design and impact design assessments were also both rated as similarly doable, with the impact assessment slightly lower rated. 


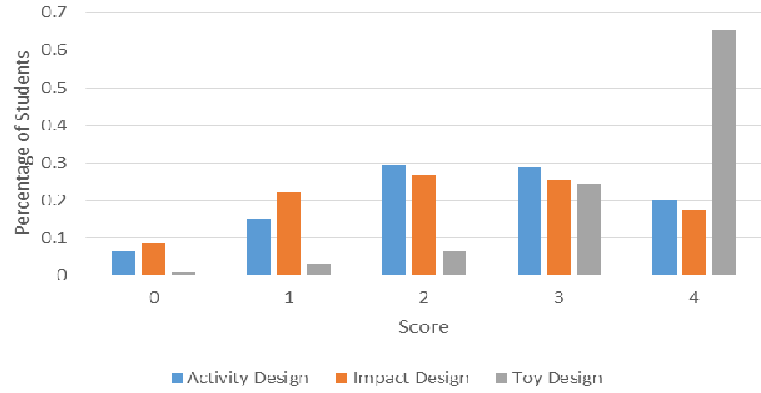

Figure 2: Student response to if the three main design assessments in ME 100 were important.

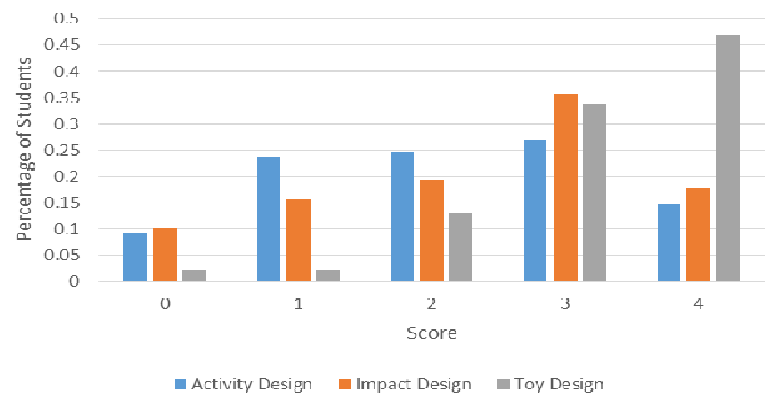

Figure 3: Student response to if the three main design assessments in ME 100 made them feel like engineers while completing them.

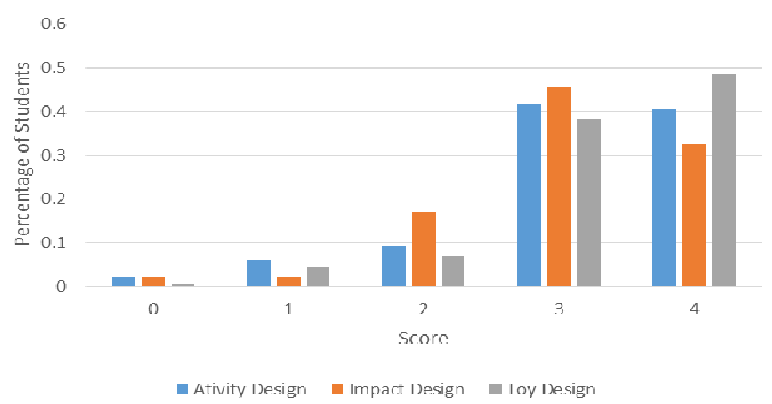

Figure 4: Student response to if the three main design assessments in ME 100 were doable with their current skills.

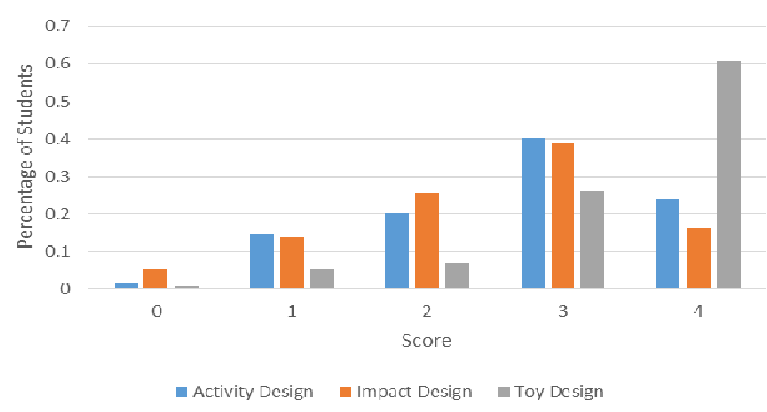

Figure 5: Student response to if the three main design assessments in ME 100 were engaging (if students enjoyed completing them).
Interestingly, the increase importance and similar doability of the impact assessment is not borne out in an increased motivation (engagement) score, as seen in Figure 5 and tabulated in Table 1. Table 1 shows the summary of engagement scores. By far the most engaging project was the cumulative project. This project required the most work, but it was also designed to be highly authentic and relatable. Furthermore, it clearly aligned with students' idea of what engineering is. From prior experience, it was expected that this would indeed be the most engaging, so the result is not surprising.

Table 1: Student report average scores of engagement (motivation) for three course projects in ME 100 F17 offering.

\begin{tabular}{|l|r|r|}
\hline Assessment & Score (max is 4) & $\begin{array}{l}\text { Standard } \\
\text { Deviation }\end{array}$ \\
\hline $\begin{array}{l}\text { Activity } \\
\text { Design }\end{array}$ & 2.35 & 1.20 \\
\hline $\begin{array}{l}\text { Impact } \\
\text { Design }\end{array}$ & 2.01 & 1.22 \\
\hline Toy Design & 3.36 & 1.04 \\
\hline
\end{tabular}

The two other projects can be compared to each other, since they were similar in scope. Both projects were not designed to be overly authentic and both were designed to be highly relatable. Their major differences was in the expectations put on the students and their context. The future course activity put much lower burden of rigour on the students, and was offered at a time when their workload was low. The impact assessment required a greater deal of effort was offered during the time they were expected to work on their final project. These distinctions can be clearly seen in their engagement scores, in which the future course activity was ranked as more engaging. We hypothesize that the major differences in context led to this difference. This hypothesis is supported by student's written feedback on the survey, with comments stating that the impact assessment, while worthwhile, was given at a point in the term when students were too busy to give it the work they felt it deserved. Student feedback included statements such as, "I think it would have been a fun activity if it hadn't been completely overshadowed by the toy design project happening at the same time,", "Was not a fan of the due date, it felt like another project added on to a lot going on. My mindset for it was to just try and get it done because I had so many things to do. It would be helpful to do this lecture and activity earlier on before the final project, so there's more time to think about it," and "I think this project was mostly neglected by my group since the toy design project was at a higher priority, and we did the assignment after we finished most of our second design project".

It is interesting to note that, in the instructor's eyes, teams were seen to perform better (being more creative, and generating more meaningful solutions) on the impact 
design project compared to the activity design project. In the future, we intend to use this information and the framework to adjust the delivery of the impact assessment. As it is an accreditation requirement and is generally important, we feel that engaging engineers on their social impacts is a relevant thing to do. However, the data clearly show that changes should be made in order to increase its engagement sore. We intend to offer this assessment at an earlier point in the term during the Fall 2018 offering of the course, when the student context has fewer other burdens, in order to see if the extra freedom increases its engagement score. It will also be interesting to see if offering the impact assessment earlier in the term will have a positive impact on performance (due to increased engagement) or negative impact (due to decreased student experience in engineering thinking).

\section{SUMMARY AND NEXT STEPS}

In this paper we have presented preliminary work toward a 'how-to' framework for designing motivating assessments. The framework is based on cognitive theories of motivation including expectancy-value and aligned and authentic objectives. These cognitive theories are reframed for designers as assessments objectives, expectations, and frame (consisting of context, authenticity, and relatability). The framework is seen to interface well with the cognitive theories.

The framework was used to design and analyze three assessments (each given as projects) in ME 100. The first project was to design an activity for an upper year course. The second (term long) project was to design a toy with industry support and guidance. The third project was to design a solution to increase the student's positive social and/or environmental impact.

The most motivating/engaging project was seen to be the toy design project, which by far was the largest scope and which also had the greatest relatability/authenticity. The two other assessments were of roughly equal authenticity/relatability measures but had differing levels of engagement, with the impact assessment seen as less engaging/motivating to students. We understand, through student surveys, that this is due to differences in student's context during the term (since the impact assessment was given at a time in the term when students were busy with the toy design project and with other courses).

With the objectives-expectations-framing framework outlined, next steps are to determine if relatability and authenticity are equally important in terms of motivation. This will require determining measures of each. We also with to test the effects of balancing authenticity, relatability, and scope. Finally, and most importantly, we must test if engaging assessments do help struggling students, students who are uncertain of their program, and/or students who tend to procrastinate.

\section{References}

[1] Claudia Bennet, Minha Ha, Julian Bennet, and Aleksander Czekanski, "Awareness of self and the engineering field: student motivation, assessment or 'fit', and preparedness for engineering education," in Proc. CEEA 2016

[2] Niksa Dubreta and Damir Milos, "Elements of Motivational Structure for Studying Mechanical Engineering," IAFOR Journal of Education, vol. 5, no. 3, pp. 89-104, 2017.

[3] Allan Wigfield and Jacquelynne Eccles, "ExpectancyValue Theory of Achievement Motivation", Contemporary Educational Psychology, vol. 25, pp. $68-81,2000$

[4] Marilla Svinicki, Learning and Motivation in the PostSecondary Classroom, Bolton, Mass., Anker Publishing Company, 2004, 263 pp. \{ISBN 1-88298259-2\}

[5] B. Simon and J. Taylor, "What is the value of Coursespecific learning goals?", Journal of College Science Teaching, Nov/Dec 2009, pp. 52-57

[6] Paul Wellington, Ian Thomas, Irene Powell, Brian Clarke, "Authentic Assessment Applied to Engineering and Business Undergrad Consulting Teams', International Journal of Engineering Education 2002, pp168-179

[7] Karl Smith, Sheri Sheppard, David Johnson, Roger Johnson, "Pedagogies of Engagement: ClassroomBased Practices", Journal of Engineering Education, January 2005, pp. 1-15

[8] Prateek Shekhar and Maura Borrego, “'Not Hard to Sway': a case study of student engagement in two large engineering classes", European Journal of Engineering Education, 2016, 10.1080/03043797.2016.1209463

[9] Helen Chen, Lisa Lattuca, and Eric Hamilton, "Conceptualizing engagement: contributions of faculty to student engagement in engineering", Journal of Engineering Education, July 2008, pp. 339-353

[10] Daniel Lopez-Fernandez, Pedro Alarcon, and Edmundo Tovar, "Motivation in Engineering Education", in Proceedings of the 2015 IEEE Global Engineering Education Conference, pp. 421-430

[11] Nick Savage, Roy Birch, and Eleni Noussi, "Motivation of engineering students in higher education", Engineering Education, vol. 6, No. 2, pp. 39-46, 2011 